\title{
Development of SSR Markers in Carnation (Dianthus caryophyllus)
}

\author{
Tetsuya Kimura ${ }^{1 *}$, Masafumi Yagi ${ }^{2}$, Chikako Nishitani ${ }^{3}$, Takashi Onozaki ${ }^{2}$, Yoshiyuki Ban ${ }^{1}$ \\ and Toshiya Yamamoto ${ }^{3}$
}

${ }^{1}$ National Center for Seeds and Seedlings, Tsukuba 305-0852, Japan

${ }^{2}$ National Institute of Floricultural Science, Tsukuba 305-8519, Japan

${ }^{3}$ National Institute of Fruit Tree Science, Tsukuba 305-8605, Japan

Thirteen SSR (simple sequence repeat) markers were successfully developed in carnation using an enriched genomic library method. All 13 primer pairs designed could successfully amplify target fragments of the expected size for the original variety 'Francesco' or 'Barbara'. Thirty-nine of 41 carnation varieties, except for mutant varieties, were successfully distinguishable using 32 putative alleles and 15 polymorphic bands produced from 13 SSR markers. 'U Conn Sim' and 'White Sim', which are bud mutants originated from 'William Sim', showed an identical genotype to 'William Sim'. Three (CB026a, CB057a, and CB060a) of 13 SSR markers were thought to be derived from multi-locus because the 3 SSR markers produced more than 3 discrete amplified fragments. The number of alleles per locus ranged from 1 (CB020a and CB041a) to 9 (CB003a), with an average value of 3.2. The values of the observed heterozygosity $\left(H_{O}\right)$ and the expected heterozygosity $\left(H_{E}\right)$ ranged from 0 to 0.59 (mean 0.30) and 0 to 0.68 (mean 0.34), respectively. The power of discrimination (PD) ranged from 0 (CB020a and CB041a) to 0.93 (CB026a) (mean 0.49). The parentage of 2 carnation varieties from intraspecific crosses was analyzed using 10 SSR markers, and the hybridity of the progenic varieties was confirmed. SSR markers were very effective for variety discrimination and determination of carnation parentage.

Key Words: Dianthus caryophyllus, genetic diversity, genetic relatedness, parentage test, simple sequence repeat.

\section{Introduction}

The genus Dianthus consists of more than 300 species and includes many important ornamental species, such as carnation (Dianthus caryophyllus L.). Carnation is one of the most important cut flower crops in the world. Many Dianthus species are also used for garden and potted plants, and are grown and distributed in temperate climate regions around the world (Mii et al., 1990). More than 30,000 varieties have been listed for Dianthus in the International Dianthus Register in England (Gatt et al., 1998). In Japan, about 1,200 varieties are listed in the new variety registration system under the seeds and seedlings law (http://www.hinsyu.maff.go.jp/, October 14, 2008). Many carnation varieties have been bred as they are one of the leading commodities in the ornamental industry (Jensen and Malter, 1995).

Recently, molecular markers have been developed and used to identify several characteristics controlling flower longevity (De Beneditti et al., 2003, 2005), resistance

Received; April 9, 2008. Accepted; August 8, 2008.

* Corresponding author (E-mail: tetsuki@affrc.go.jp). to disease (Onozaki et al., 1999, 2004; Scovel et al., 2001; Yagi et al., 2006), and double flowers (Scovel et al., 1998) in carnation breeding programs. Molecular markers have been also utilized to confirm interspecific hybrids (Nimura et al., 2003, 2006) and variety identification (Smulders et al., 2000, 2003).

In humans and animals, SSR markers of a single locus have been used in parentage analysis and criminal investigations (Glowatzki-Mullis et al., 1996; Hughes, 1992). SSR markers have several advantages over other molecular markers in that they provide a more reliable method for DNA fingerprinting because of their codominant inheritance and large number of alleles per locus; therefore, SSR markers can be utilized for variety identification, parentage analysis and genetic relatedness. SSR markers are expected to be used in DNA profiling techniques in order to protect the rights of the breeders of a new plant variety (http://www.hinsyu. maff.go.jp/, October 14, 2008).

In previous studies, we established genomic libraries enriched for di-nucleotide repeat motifs and developed SSR markers for pear, peach, and rose (Kimura et al., 2006; Yamamoto et al., 2002a, 2002b, 2002c). The 
developed SSR markers were successfully utilized to construct genetic linkage maps, genetic identification, and parentage analysis in pear (Kimura et al., 2002, 2003, 2006; Yamamoto et al., 2002b, 2006).

Smulders et al. $(2000,2003)$ reported that the 8 simple sequence repeat (SSR) markers developed could be used to evaluate the genetic diversity of Dianthus species and identify carnation varieties. However, the number of SSR markers is still limited for efficient variety identification and confirmation of hybrids in carnation; therefore, it is necessary to increase the number of SSR markers for genetic studies.

In this study, we isolated and developed polymorphic SSRs from enriched genomic libraries of carnation varieties. Genetic identification of 41 standard- and spray-type varieties was performed using established SSR markers. The hybridity of 2 varieties derived from 2 combinations of intraspecific crosses was examined using 10 SSR markers.

\section{Materials and Methods}

\section{Plant materials and DNA extraction}

Genomic DNAs used for SSR isolation were extracted for a standard-type variety 'Francesco' and a spray-type variety 'Barbara' using a Genomic-tip20/G column and the G2 Buffer method (Yamamoto et al., 2006).

Forty-one carnation (Dianthus caryophyllus L.) varieties, were used including 23 standard-type and 18 spray-type varieties (Table 1). Plant materials were obtained from the National Center for Seeds and Seedlings (NCSS, Tsukuba, Japan) and the National Institute of Floricultural Science (NIFS, Tsukuba, Japan). 'Miracle Rouge', ' $85-11$ ' and their parent varieties were used for hybrid confirmation.

Genomic DNAs were isolated from fresh young leaves using the DNeasy Plant Mini Kit (Qiagen, Japan) according to the manufacturer's instructions. One hundred milligrams of fresh leaf tissue was homogenized in liquid nitrogen. The tissue powder obtained was suspended in $400 \mu \mathrm{L}$ AP1 lysis buffer, $4 \mu \mathrm{L}$ RNase A solution $\left(100 \mathrm{mg} \cdot \mathrm{ml}^{-1}\right), 8 \mu \mathrm{L}$ 2-mercaptoethanol and $100 \mathrm{mg}$ polyclar $\mathrm{AT}$, and then incubated at $65^{\circ} \mathrm{C}$ for 10 minutes. One hundred and thirty microliters of AP2 buffer was added to the solution and put on ice for 5 minutes. After centrifugation at $15,000 \mathrm{rpm}$ for $10 \mathrm{~min}$, the solution was applied to the QIAshredder spin column. After centrifugation, the flow-through fraction was recovered. AP3 buffer was added to the suspension and then added to the DNeasy Plant Mini Prep Column. After washing with AW buffer, genomic DNA was eluted with $50 \mu \mathrm{L}$ of sterilized Milli-Q water.

\section{SSR isolation}

Enriched genomic libraries were constructed from 'Francesco' and 'Barbara'. Genomic DNAs were digested with Eco RI and Mse I, and then ligated into adaptors using the AFLP Analysis System I (Invitrogen,
USA) at twice the scale of the manufacturer's instructions. Pre-PCR was conducted using Eco-primer (5'-GACTGCGTACCAATTC-3') and Mse-primer (5'GATGAGTCCTGAGTAA-3'). Amplification was performed in a $200 \mu \mathrm{L}$ solution of $10 \mathrm{mM}$ Tris- $\mathrm{HCl}(\mathrm{pH} 8.3)$, $50 \mathrm{mM} \mathrm{KCl}, 1.5 \mathrm{mM} \mathrm{MgCl}_{2}, 0.01 \%$ gelatin, $0.2 \mathrm{mM}$ each of dNTPs, 10 pmoles of Eco-primer and 60 pmoles of Mse-primer, adaptor-ligated DNA, and 10 units of Taq DNA polymerase (Invitrogen). Amplification was performed with $5-10$ cycles at $90^{\circ} \mathrm{C}$ for $30 \mathrm{~s}, 56^{\circ} \mathrm{C}$ for $60 \mathrm{~s}$, and $72^{\circ} \mathrm{C}$ for $60 \mathrm{~s}$, for denaturing, annealing and primer extension, respectively. PCR products were hybridized with 100 pmoles of 3'-biotin-labelled (AG) 15 oligonucleotides after denaturation. The sample obtained was mixed thoroughly with $100 \mu \mathrm{g}$ of Dynabeads M280 Streptavidin (Dynal, Norway) in STEX buffer $(100 \mathrm{mM} \mathrm{NaCl}, 10 \mathrm{mM}$ Tris-HCl, $1 \mathrm{mM}$ EDTA, $0.1 \%$ Triton X-100, $\mathrm{pH} 8.0$ ) for $30 \mathrm{~min}$.

The conjugates were collected with a magnet and washed with STEX buffer 3 times. The washed conjugates were suspended in 1/10 TE $(10 \mathrm{mM}$ Tris$\mathrm{HCl}, 0.1 \mathrm{mM}$ EDTA, $\mathrm{pH} 8.0$ ). After boiling for $3 \mathrm{~min}$., the target DNAs were recovered from the supernatant solution. PCR was conducted using the enriched DNAs as templates under the same conditions as for pre-PCR except that 25 cycles were adopted. The PCR products were ligated into the pCR2.1 vector and transformed into competent Escherichia coli cells (Original TA Cloning Kit, Invitrogen). Colony blot hybridization was performed to select the plasmids containing repeat sequences. Recombinants were transferred onto nylon membranes (Hybond $\mathrm{N}^{+}$, Amersham, UK) and then hybridized with 5 '-biotin-(AG) $)_{15}$ oligonucleotides as a probe. Positive clones were detected using the BrightStar BioDetect kit (Ambion, USA), according to the manufacturer's instructions. Positive plasmids were sequenced using a PRISM 377 DNA sequencer (PEApplied Biosystems, USA) after cycle sequence reaction with BigDye Terminator Cycle Sequencing Kit (PEApplied Biosystems). SSR primer sets were designed using the software OLIGO ver. 6.0 (Molecular Biology Insights, USA).

\section{PCR amplification of SSRs}

Thirteen SSR primer pairs originating from enriched SSR clones were used for PCR amplification (Table 2). PCR amplification was performed in a $20 \mu \mathrm{L}$ solution of $10 \mathrm{mM}$ Tris- $\mathrm{HCl}(\mathrm{pH} 8.3), 50 \mathrm{mM} \mathrm{KCl}, 1.5 \mathrm{mM}$ $\mathrm{MgCl}_{2}, 0.01 \%$ gelatin, $0.2 \mathrm{mM}$ each of dNTPs, 10 pmoles of each forward primer labeled with fluorescent chemicals (Fam, Ned or Vic) and unlabelled reverse primer, $10 \mathrm{ng}$ of genomic DNA, and 0.5 unit of Taq DNA polymerase (Invitrogen). Amplification was performed with 35 cycles at $94^{\circ} \mathrm{C}$ for $1 \mathrm{~min}, 55-60^{\circ} \mathrm{C}$ for $1 \mathrm{~min}$ and $72^{\circ} \mathrm{C}$ for $2 \mathrm{~min}$, for denaturation, annealing, and primer extension, respectively. PCR products were separated and detected using a PRISM 3100 DNA 
Table 1. Plant materials used in this study.

\begin{tabular}{|c|c|c|c|}
\hline No. & Variety name & Flower type & Source $^{z}$ \\
\hline 1 & Aicardi & standard & NCSS \\
\hline 2 & Brelag & standard & NCSS \\
\hline 3 & Design & standard & NCSS \\
\hline 4 & Empire & standard & NCSS \\
\hline 5 & Felix & standard & NCSS \\
\hline 6 & Francesco & standard & NCSS \\
\hline 7 & Keipacks & standard & NCSS \\
\hline 8 & Kobuchi Santo & standard & NCSS \\
\hline 9 & Laville Dorina & standard & NCSS \\
\hline 10 & Miracle Rouge & standard & NIFS, hybrid of $63-41$ and $62-48$ \\
\hline 11 & Novelpink & standard & NCSS \\
\hline 12 & Opera & standard & NCSS \\
\hline 13 & Riccardo & standard & NCSS \\
\hline 14 & Saleya & standard & NCSS \\
\hline 15 & Sorriso & standard & NCSS \\
\hline 16 & U conn Sim & standard & NIFS, bud mutant from William Sim \\
\hline 17 & White Sim & standard & NIFS, bud mutant from William Sim \\
\hline 18 & William Sim & standard & NIFS \\
\hline 19 & $62-48$ & standard & NIFS, male parent of Miracle Rouge \\
\hline 20 & $63-7$ & standard & NIFS, male parent of $85-11$ \\
\hline 21 & $63-35$ & standard & NIFS, female parent of $85-11$ \\
\hline 22 & $63-41$ & standard & NIFS, female parent of Miracle Rouge \\
\hline 23 & $85-11$ & standard & NIFS, hybrid of $63-35$ and $63-7$ \\
\hline 24 & Alicetta & spray & NCSS \\
\hline 25 & Alpine Rose & spray & NCSS \\
\hline 26 & Barbara & spray & NCSS \\
\hline 27 & Breime & spray & NCSS \\
\hline 28 & Breto & spray & NCSS \\
\hline 29 & Bridal White & spray & NCSS \\
\hline 30 & CFPC Rose Malea & spray & NCSS \\
\hline 31 & Hilfines & spray & NCSS \\
\hline 32 & HY Bis & spray & NCSS \\
\hline 33 & Kleoya & spray & NCSS \\
\hline 34 & Koreno & spray & NCSS \\
\hline 35 & Lilac & spray & NCSS \\
\hline 36 & Mystic Green & spray & NCSS \\
\hline 37 & Ronia & spray & NCSS \\
\hline 38 & Rose Clavel & spray & NCSS \\
\hline 39 & Stadisoc & spray & NCSS \\
\hline 40 & Super Gold & spray & NIFS \\
\hline 41 & Vega & spray & NCSS \\
\hline
\end{tabular}

${ }^{z}$ Abbreviations of varieties sources are as follows. NCSS: National Center for Seeds and Seedlings, NIFS: National Institute of Floricultural Science.

sequencer (Applied Biosystems). The size of the amplified products was calculated based on internal standard DNA (HD400ROX, Applied Biosystems) using GeneScan software (Applied Biosystems).

\section{Statistical analysis}

The heterozygosity and power of discrimination of carnations were estimated for SSR loci. The observed heterozygosity $\left(H_{O}\right)$ and the expected heterozygosity $\left(H_{E}\right)$ were calculated using CERVUS ver. 2.0 software
(Marshall et al., 1998). $H_{O}$ was calculated as the number of heterozygous genotypes at a given locus divided by the total number of genotypes scored at that locus. $H_{E}$ was calculated using an unbiased formula from allele frequencies assuming Hardy-Weinberg equilibrium (equation 8.4, Nei, 1987). The power of discrimination (PD) was calculated based on the frequency of each genotype according to the formula: $\mathrm{PD}=1-\Sigma \mathrm{p} i^{2}$ where $\mathrm{p} i$ is the frequency of the $i^{\text {th }}$ genotype of each SSR locus (Kloosterman et al., 1993). A phenogram of 41 varieties 


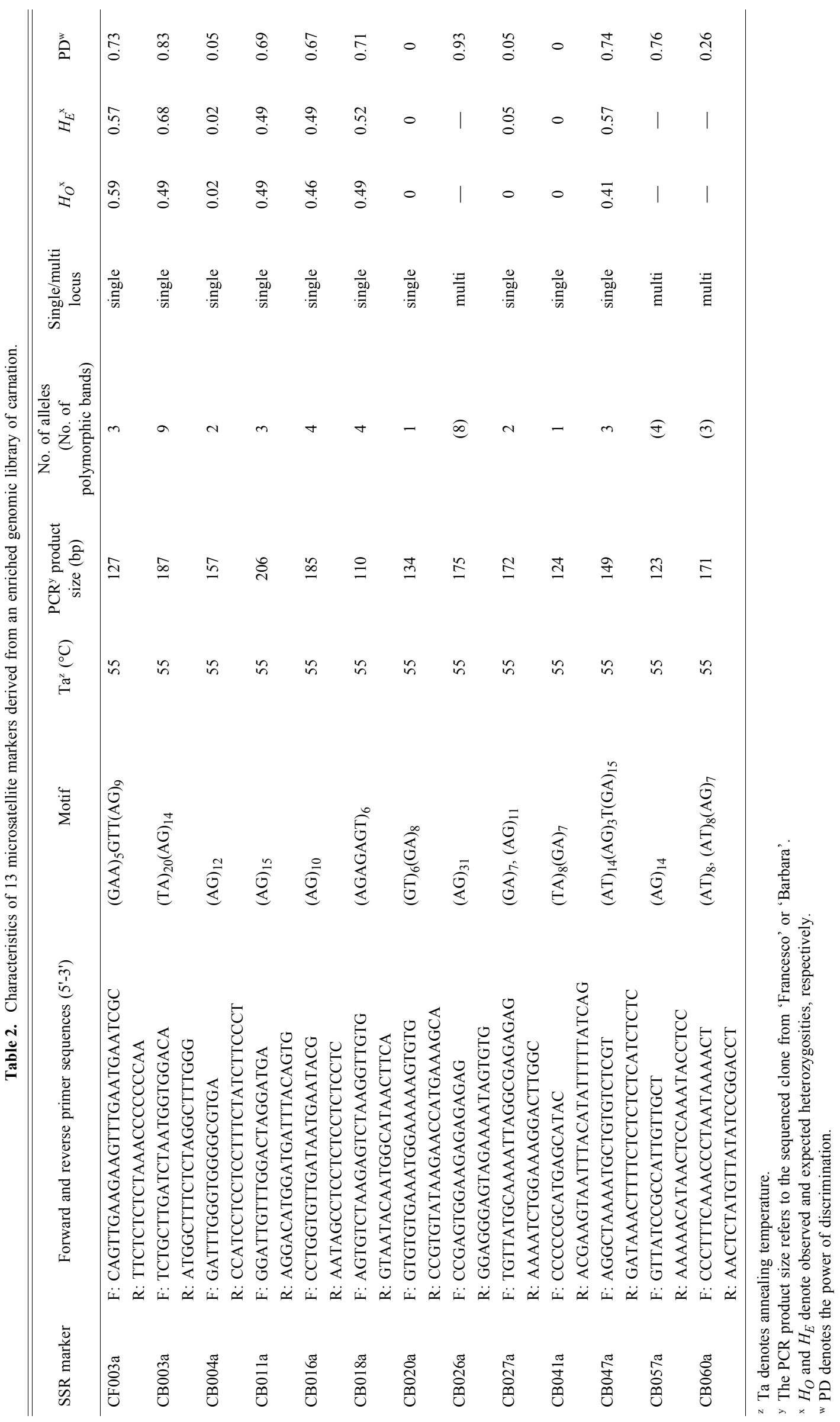


was constructed using UPGMA (unweighted pair-group method using arithmetic averages) based on Nei's genetic identity (Nei and Li, 1979). The program NTSYS-pc, ver. 2.01 was used to construct the phenogram (Rohlf, 1998). Parentage was analyzed based on the inheritance of one allele at a single SSR locus transmitted from the parent to the offspring.

\section{Results and Discussion}

\section{SSR marker development}

A total of 141 positive clones were screened from 615 colonies with genomic libraries enriched for $(\mathrm{AG}) /(\mathrm{TC})$ of carnation varieties 'Francesco' and 'Barbara' by blot hybridization. After sequencing these positive clones, 62 independent sequences containing 7 or more repeat motifs were obtained with ca. 13.0 repeats on average. The average insert size of the clones obtained was ca. $381 \mathrm{bp}$, ranging from $101 \mathrm{bp}$ to $997 \mathrm{bp}$. Only one set of sequences showed duplication. Of 62 sequences, 48 contained complete $(\mathrm{AG}) /(\mathrm{TC})$ repeats and the others had interrupted repeats or combined motifs of $(\mathrm{AG}) /(\mathrm{TC})$ and other units. For example, the CB018a SSR sequence contained 6 repeats of complete (AGAGAGT)/ (TCTCTCA) (Table 2). Six sequences showed 2 repeat regions apart from each.

In our previous studies, SSR markers were developed from pear and rose (Kimura et al., 2006; Yamamoto et al., 2002a), in which 107 and 83 positive clones were screened from 927 and 192 clones, respectively. Eightyfive independent sequences were obtained containing 8 or more repeat motifs in pear, and 55 independent sequences contained 7 or more repeat motifs in rose. The rate of independent sequences containing the repeat motif for the positive clones was $9.2 \%$ and $16.1 \%$ in pear and rose, respectively. In this study, the rate of independent sequences containing the repeat motif was $10.1 \%$ in carnation, which showed a similar value of that of pear. The average number of repeats in independent sequences containing repeat motifs was ca. 20.0 and 16.1 in pear and rose, respectively. The number of ca. 13.0 repeats on average in carnation was less than in pear and rose. The average insert size of ca. $381 \mathrm{bp}$ obtained in carnation was larger than ca. $360 \mathrm{bp}$ in pear and smaller than $489 \mathrm{bp}$ of rose. The number of sequences containing complete $(\mathrm{AG}) /(\mathrm{TC})$ repeats in carnation was greater than that of sequences with interrupted repeats or combined motifs, as observed in pear and rose. The rate of sequences containing complete (AG)/(TC) repeats in carnation was $77.4 \%$, which was larger than the $69.4 \%$ in pear and $65.5 \%$ in rose. SSR markers could be successfully established from enriched genomic libraries of carnation varieties by the same method applied for pear and rose.

\section{Genetic variation evaluated by SSR markers}

Thirteen SSR markers were used to evaluate genetic variation in 41 carnation varieties. All 13 primer pairs designed could successfully amplify the target fragments of the expected size for the original variety 'Francesco' or 'Barbara' (Table 2). Ten SSR markers (CF003a, CB003a, CB004a, CB011a, CB016a, CB018a, CB020a, $\mathrm{CB} 027 \mathrm{a}, \mathrm{CB} 041 \mathrm{a}$, and CB047a) produced 1 or 2 discrete amplified fragments for 41 carnation varieties. In particular, the shape of amplified fragments by CB018a SSR was simple and easy for scoring. On the other hand, the 3 SSR markers (CB026a, CB057a, and CB060a) produced 3 or more discrete amplified fragments. Since most carnation varieties are diploid with a chromosome number of $2 \mathrm{n}=30$ (Gatt et al., 1998), these 3 SSR markers might amplify 2 or more loci.

Standard carnation varieties, 'U Conn Sim', 'White Sim' and 'William Sim', stored at NIFS showed identical peak patterns in all used SSR markers shown as group $B$ in Figure 1. It was reported that both 'U Conn Sim' and 'White Sim' were bud mutants originating from 'William Sim' (Mato et al., 2000), and the current results of SSR analysis accorded with the breeding process. Thirty-nine of 41 carnation varieties except for mutant varieties, were successfully distinguished using 32 putative alleles and 15 polymorphic bands produced from 13 SSR markers (Table 2 and Fig. 1). It was considered that SSR analysis is a very effective tool for variety identification in carnation.

In $\mathrm{F}_{1}$ varieties of 'Miracle Rouge' and ' $85-11$ ' bred from intraspecific crosses of D. caryophyllus L., 10 of the 13 SSR markers produced 1 or 2 discrete amplified fragments. On the other hand, the other 3 SSR markers (CB026a, CB057a, and CB060a) produced more than 3 discrete amplified fragments, which were not applied for hybridity confirmation. In the hybridity confirmation of 'Miracle Rouge', 4 SSR loci (CF003a, CB003a, CB011a, and CB018a) showed more than 2 putative alleles at all 4 SSR loci. The other 6 SSR loci showed identical SSR genotypes for both parents. The alleles of $128 \mathrm{bp}$ and $128 \mathrm{bp}$ of 'Miracle Rouge' at SSR CF003a were inherited from '63-41' and '62-48', respectively (Table 3). Similarly, the alleles of $190 \mathrm{bp}$ and $203 \mathrm{bp}$ at CB003a were transmitted from ' $63-41$ ' and '62-48', respectively. For the other two SSR markers, the alleles of $210 \mathrm{bp}$ and $214 \mathrm{bp}$ at CB011a and the alleles of $93 \mathrm{bp}$ and $98 \mathrm{bp}$ at CB018a were also inherited from ' $63-41$ ' and ' $62-48$ ', respectively.

In the parentage of ' $85-11$ ', 5 SSR loci (CF003a, CB003a, CB011a, CB018a, and CB047a) showed more than 2 putative alleles at all 5 SSR loci. SSR alleles of 210 bp and 214 bp of ' $85-11$ ' at CB011a were inherited from '63-35' and '63-7', respectively (Table 3). Similarly, the SSR alleles of ' $85-11$ ' were inherited from its parent variety without discrepancy for the other 4 SSRs CF003a, CB003a, CB018a, and CB047a; therefore, parent-offspring relationships of both 'Miracle Rouge' and ' $85-11$ ' confirmed that the hybrids inherited SSR alleles from their parents without any discrepancy. It is considered that SSR analysis was very useful for 


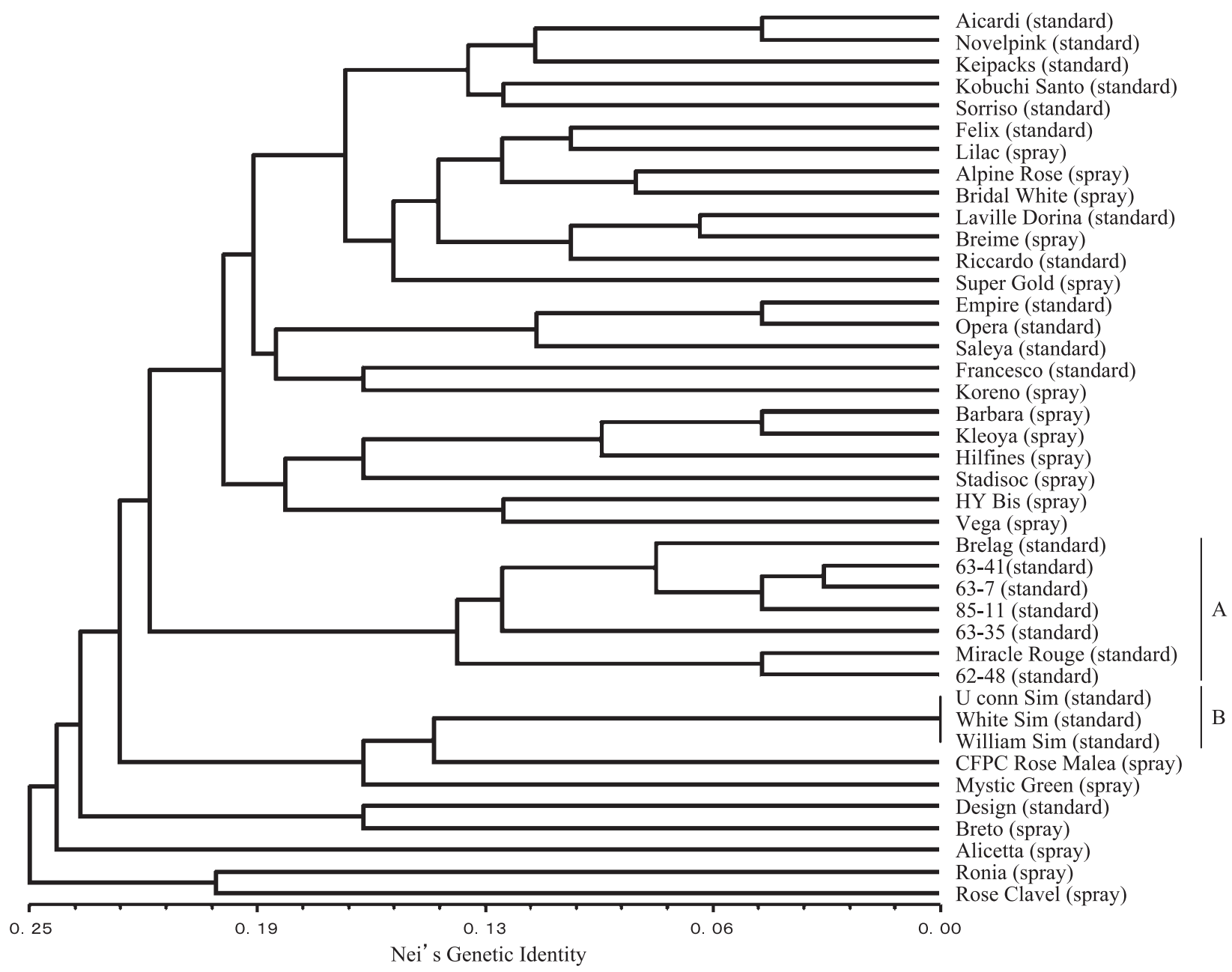

Fig. 1. Phenogram of the 41 genotypes of standard- and spray-type varieties of carnation. The phenogram was produced using the UPGMA method of Nei's genetic identity (Nei and Li, 1979) between varieties.

hybridity confirmation in carnation.

Ten SSR loci, except for CB026a, CB057a, and $\mathrm{CB} 060 \mathrm{a}$, were used to evaluate genetic variation derived from a single locus. The number of alleles per locus ranged from 1 for CB020a and CB041a to 9 for CB003a, with an average value of 3.2 (Table 2 ). The average value of the observed heterozygosity $\left(H_{O}\right)$ among the 10 loci was 0.30 , ranging from $0(\mathrm{CB} 020 \mathrm{a}, \mathrm{CB} 027 \mathrm{a}$, and $\mathrm{CB} 041 \mathrm{a})$ to 0.59 (CF003a). The average value of the expected heterozygosity $\left(H_{E}\right)$ among the 10 loci was 0.34 , ranging from 0 (CB020a, CB027a, and CB041a) to 0.68 (CB003a). The value of the observed heterozygosity $\left(H_{O}\right)$ was relatively lower than that in Smulenders et al. (2003), reflecting that genetically restricted varieties of double flower phenotypes might be used in this study. The power of discrimination (PD) in the 13 SSR markers ranged from 0 (CB020a, CB041a) to 0.93 (CB026a) with a mean value of 0.49 .

Carnation varieties are usually identified based on morphological characteristics; however, it has been pointed out that phenotypic traits are often influenced by environmental conditions and human judgments. For example, some standard- and spray-type varieties do not have easily distinguishable flower characteristics due to phenotypic overlaps caused by environmental conditions, even if standard- and spray-type varieties usually have double and semi-double flower characteristics, respectively (Scovel et al., 1998).

For the genetic relatedness of 41 carnation varieties, analysis based on SSR genotypes revealed that they were mixed among standard- and spray-type varieties (Fig. 1). It was described that the first spray-type variety was a mutant originated from 'William Sim' at 1952 (Hosoya, 1999). As each spray-type variety was derived from the standard type with various genotypes, standard and spray varieties were mixed by UPGMA analysis.

Seven varieties ('Miracle Rouge', '62-48', '63-7', '6335 ', '63-41', '85-11', and 'Brelag') were grouped to form cluster group A. Six varieties, except for 'Brelag'; were obtained from NIFS (Fig. 1). Two pairs showing parent-offspring relationships were grouped very closely. For example, '62-48' (male parent) vs. 'Miracle Rouge' (offspring) and '63-7' (male parent) vs. '85-11' (offspring) showed high genetic identity, and '63-7', 


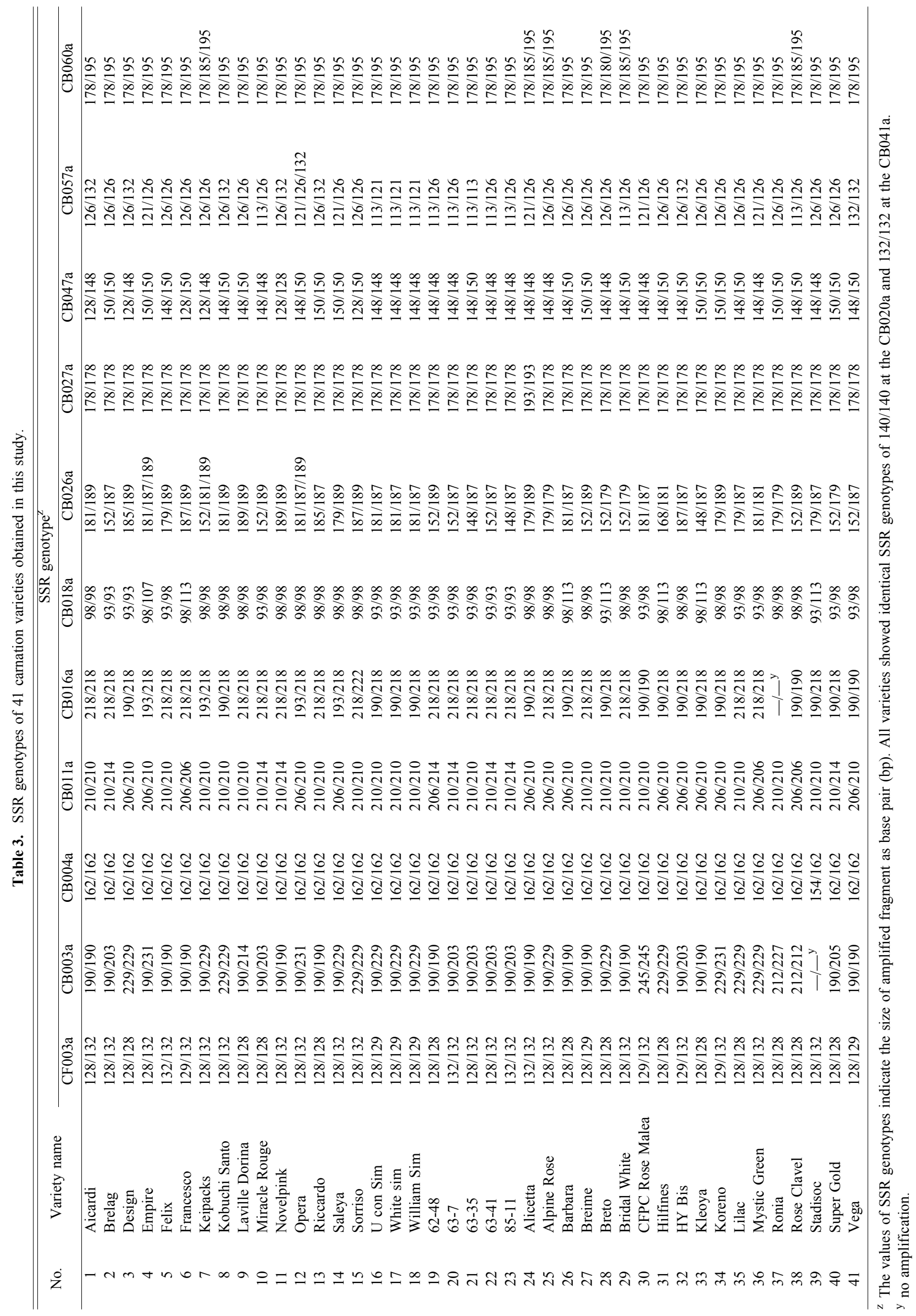


'63-41', and '63-48' were $F_{1}$ hybrids derived from the same cross of '945-1' and '945-17' (Onozaki et al., 2006), therefore, it was considered that the results obtained were quite reasonable.

In this study, we could successfully develop 13 SSR carnation markers. These SSR markers will be utilized for genetic identification and hybridity confirmation of intraspecific crosses, and are expected to be put to practical use to protect the rights of breeders as a DNA carnation profiling technique. SSR markers and DNA profiling systems of mat-rush (Juncus effusus L.), small beans, sweet cherry and pear are used to protect the rights of breeders (http://www.hinsyu.maff.go.jp/, October 14, 2008); however, the number of SSR markers is still limited for DNA profiling in other plant species. Many DNA markers, such as SSR markers, are needed to support the variety registration system under the seeds and seedlings law based on UPOV (International Union for the Protection of New Plant Varieties, Switzerland). Furthermore, it is necessary to develop many more SSR markers for various plants to be put to practical use in DNA profiling.

\section{Acknowledgements}

The authors are grateful to Dr. H. Iketani for his valuable suggestions and guidance. We are also grateful to Dr. S. Terakami, Mrs. M. Osono, N. Asano and T. Imai for their useful discussions.

\section{Literature Cited}

De Beneditti, L., G. Burchi, S. Bruna, A. Mercuri and T. Schiva. 2003. Use of molecular markers to improve cut flowers longevity in carnation. Acta Hort. 624: 343-348.

De Beneditti, L., L. Braglia, S. Bruna, G. Burchi, A. Mercuri and T. Schiva. 2005. PCR-based markers and cut flower longevity in carnation. Acta Hort. 683: 437-443.

Gatt, M. K., K. R. W. Hammett, K. R. Markham and B. G. Murray. 1998. Yellow pinks: interspecific hybridization between Dianthus plumarius and related species with yellow flowers. Sci. Hort. 77: 207-218.

Glowatzki-Mullis, M. L., L. Ritz and C. Gaillard. 1996. PCR-an important step to conclusive paternity in parentage control cases of cattles. Schweiz. Arch. Tierheilk. 138: 161-166.

Hosoya, M. 1999. Transition and trend in carnation cultivars. Agriculture and Horticulture 74: 23-30 (In Japanese).

Hughes, A. E. 1992. Optimization of microsatellite analysis for genetic mapping. Genomics 15: 433-434.

Jensen, M. H. and A. J. Malter. 1995. Protected agriculture, a global review. World Bank Technical Paper 253: 144-146.

Kimura, T., Y. Z. Shi, M. Shoda, K. Kotobuki, N. Matsuta, T. Hayashi, Y. Ban and T. Yamamoto. 2002. Identification of Asian pear varieties by SSR analysis. Breed. Sci. 52: 115-121.

Kimura, T., Y. Sawamura, K. Kotobuki, N. Matsuta, T. Hayashi, Y. Ban and T. Yamamoto. 2003. Parentage analysis characterized by SSR markers in pear cultivars. J. Japan. Soc. Hort. Sci. 72: 182-189.

Kimura, T., C. Nishitani, H. Iketani, Y. Ban and T. Yamamoto. 2006. Development of microsatellite markers in rose. Mol. Ecol. Notes 6: 810-812.

Kloosterman, A. D., B. Budowle and P. Daselaar. 1993. PCR amplification and detection of the human D1S80 VNTR locus. Amplification conditions, population genetics and application in forensic analysis. Int. J. Leg. Med. 105: 257-264.

Mato, M., T. Onozaki, Y. Ozeki, D. Higeta, Y. Itoh, Y. Yoshimoto, H. Ikeda, H. Yoshida and M. Shibata. 2000. Flavonoid biosynthesis in white-flowered Sim carnations (Dianthus caryophyllus). Sci. Hort. 84: 333-347.

Marshall, T. C., J. Slate, L. Kruuk and J. M. Pemberton. 1998. Statistical confidence for likelihood-based paternity inference in natural populations. Mol. Ecol. 7: 639-655.

Mii, M., M. Buiatti and F. Gimelli. 1990. Carnation. p. 284-318. In: P. V. Ammirato, D. A. Evans, W. R. Sharp and Y. P. S. Bajaj (eds.). Handbook of Plant Cell Culture 5. McGraw-Hill Publishing Company, New York.

Nei, M. 1987. Molecular Evolutionary Genetics. Columbia University Press, New York.

Nei, M. and W. H. Li. 1979. Mathematical model for studying genetic variation in terms of restriction endonucleases. Proc. Natl. Acad. Sci. USA 76: 5269-5273.

Nimura, M., J. Kato, M. Mii and K. Morioka. 2003. Unilateral compatibility and genotypic difference in crossability in interspecific hybridization between Dianthus caryophyllus L. and Dianthus japonicaus Thunb. Theor. Appl. Genet. 106: 1164-1170.

Nimura, M., J. Kato, M. Mii and T. Katoh. 2006. Amphidiploids produced by natural chromosome-doubling in inter-specific hybrids between Dianthus $\times$ isensis Hirahata et Kitam. and D. japonicus Thunb. J. Hort. Sci. Biotech. 81: 71-77.

Onozaki, T., T. Yamaguchi, M. Himeno and H. Ikeda. 1999. Evaluation of 227 carnation for resistance to bacterial wilt (Pseudomonas caryophylli). J. Japan. Soc. Hort. Sci. 68: 546550.

Onozaki, T., N. Tanikawa, M. Taneya, K. Kubo, T. Funayama, H. Ikeda and M. Shibata. 2004. A RAPD-derived STS marker is linked to a bacterial wilt (Burkholderia caryophylli) resistance gene in carnation. Euphytica 138: 255-262.

Onozaki, T., H. Ikeda, M. Shibata, N. Tanikawa, M. Yagi, T. Yamaguchi and M. Amano. 2006. Breeding process and characteristics of carnation Norin No. 1 'Miracle Rouge' and No. 2 'Miracle Symphony' with long vase life. Bull. Natl. Inst. Flor. Sci. 5: 1-16

Rohlf, F. J. 1998. NTSYS-pc, Numerical Taxonomy and Multivariate Analysis System, Version 2.01. Exeter Publishing, Ltd., Setauket, New York.

Scovel, G., H. Ben-Meir, M. Ovadis, H. Itzhaki and A. Vainstein. 1998. RAPD and RFLP markers tightly linked to the locus controlling carnation (Dianthus caryophyllus) flower type. Theor. Appl. Genet. 96: 117-122.

Scovel, G., M. Ovadis, A. Vainstein, M. Reuven and Y. BenYephet. 2001. Marker assisted selection for resistance to Fusarium oxysporum in the greenhouse carnation. Acta Hort. 552: $151-156$.

Smulders, M. J. M., W. Rus-Kortekaas and B. Vosman. 2000. Microsatellite markers useful throughout the genus Dianthus. Genome 43: 208-210.

Smulders, M. J. M., Y. Noordijk, W. Rus-Kortekaas, G. M. M. Bredemeijer and B. Vosman. 2003. Microsatellite genotyping of carnation varieties. Theor. Appl. Genet. 106: 1191-1195.

Yagi, M., T. Onozaki, M. Taneya, H. Watanabe, T. Yoshimura, T. Yoshinari, Y. Ochiai and M. Shibata. 2006. Construction of a genetic linkage map for the carnation by using RAPD and SSR markers and mapping quantitative trait loci (QTL) for resistance to bacterial wilt caused by Burkholderia caryophylli. J. Japan. Soc. Hort. Sci. 75: 166-172.

Yamamoto, T., T. Kimura, Y. Ban, M. Shoda, T. Hayashi and N. 
Matsuta. 2002a. Development of microsatellite markers in Japanese pear (Pyrus pyrifolia Nakai). Mol. Ecol. Notes 2: 14-16.

Yamamoto, T., T. Kimura, M. Shoda, T. Imai, T. Saito, Y. Sawamura, K. Kotobuki, T. Hayashi and N. Matsuta. 2002b. Genetic linkage maps constructed by using an interspecific cross between Japanese and European pears. Theor. Appl. Genet. 106: 9-18.
Yamamoto, T., K. Mochida, T. Imai, Y. Z. Shi, I. Ogiwara and T. Hayashi. 2002c. Microsatellite markers in peach [Prunus persica (L.) Batsch] derived from an enriched genomic and cDNA libraries. Mol. Ecol. Notes 2: 298-301.

Yamamoto, T., T. Kimura, T. Hayashi and Y. Ban. 2006. DNA profiling of fresh and processed fruits in pear. Breed. Sci. 56: $165-171$. 